\title{
Modulation of cancer-specific immune responses by amino acid degrading enzymes
}

To evade immune destruction, tumors exploit a wide range of immune escape mechanisms, including the induction of an immunosuppressive tumor microenvironment. This is mediated, in part, by amino acid degrading enzymes indoleamine 2,3-dioxygenase, tryptophan 2,3-dioxygenase, arginase 1 and arginase 2 , which have emerged as key players in the regulation of tumor-induced immune tolerance. Here we describe how the expression of tryptophan- and argininedegrading enzymes by tumor and tumor-infiltrating cells can hamper cancer-specific immune responses, and discuss how this knowledge is being exploited to develop new strategies for cancer immunotherapy.

First draft submitted: 3 October 2016; Accepted for publication: 14 November 2016; Published online: 21 December 2016

Keywords: arginase $\bullet$ immunosuppression $\bullet$ indoleamine 2,3-dioxygenase $\bullet$ tryptophan 2,3-dioxygenase $\bullet$ tumor microenvironment

\section{Diverse mechanisms of tumor immune evasion}

Although the immune system is able to detect and destroy transformed cells, most tumors evade immune destruction through exploitation of a wide range of immune escape mechanisms. Some of these include impairment of MHC-mediated tumor antigen presentation, activation of proapoptotic pathways and downregulation of costimulatory molecules of the B7 family, which lead to T-cell anergy, as well interference with TCR signaling (reviewed in [1]). Importantly, there is a growing body of evidence demonstrating that tumors can promote the development of an immunosuppressive microenvironment. This can be achieved by the production of anti-inflammatory mediators, such as prostaglandin E2 (PGE2), TGF- $\beta$ and IL-10, exploitation of inhibitory molecules of the B7 family, such as PD-L1, and recruitment of immunoregulatory cells, such as Treg cells and tolerogenic myeloid populations. The latter include specific subsets of myeloid dendritic cells (DCs), plasmacytoid DCs (pDCs), tumor-associated macrophages (TAMs) and myeloid-derived suppressor cells (MDSCs) capable of secreting anti-inflammatory cytokines and expressing immunosuppressive metabolic enzymes, such as inducible nitric oxide synthase (iNOS), indoleamine 2,3-dioxygenase (IDO) and arginase (reviewed in [2]). Some of these inhibitory mediators, particularly the amino acid degrading enzymes, which are the topic of this review, can also be expressed by tumor cells themselves, leading to further establishment of immunological tolerance. Below, we introduce the two types of amino acid degrading enzymes, tryptophan- and arginine-degrading enzymes, known to be the major players in mediating tumor immune evasion. We further detail their mechanisms of action on cancerspecific immune responses, both at the level of the tumor cells and of tumor-associated cells, and finally describe how this knowledge is being exploited to develop anticancer therapeutics, some of which are currently showing early promise in clinical trials.
Elina Timosenko ${ }^{\dagger, 1}$, Andreas $\checkmark$ Hadjinicolaou ${ }^{\dagger, 1}$ \& Vincenzo Cerundolo*,1

'MRC Human Immunology Unit, Weatherall Institute of Molecular Medicine, University of Oxford, John Radcliffe Hospital, Oxford, OX3 9DS, UK *Author for correspondence: Tel.: +44186522 2412 Fax: +44186522 2502 vincenzo.cerundolo@imm.ox.ac.uk ${ }^{\dagger}$ Authors contributed equally
Future : Medicine part of 


\section{Amino acid degrading enzymes \& their physiological roles}

Tryptophan-degrading enzymes

IDO and tryptophan 2,3-dioxygenase (TDO) are rate-limiting enzymes of the kynurenine pathway, which convert tryptophan, the least abundant of all essential amino acids, into its metabolite kynurenine. There are two paralogs of the IDO enzyme, IDO1 and the less studied IDO2 paralog. Although these three heme dioxygenases catalyze the same reaction in the kynurenine pathway, there are substantial differences in their biochemical properties, molecular regulation and expression pattern. IDO1 is widely expressed in various tissues, including the placenta, gut and lung [3], and can be induced in several cell types in response to IFN- $\gamma$, including macrophages [4] and specific subsets of DCs [5]. In addition to proinflammatory cytokines, physiological inducers of IDO1 include Toll-like receptor ligands, hormones, lipid molecules, such as PGE2 [6], as well as cell-contact-dependent stimuli involving B7:CTLA-4 and other interactions [7,8]. In contrast, TDO (encoded by TDO2) expression is mainly restricted to the liver and the brain [9], and is largely unresponsive to immunological stimuli.

It has been long recognized that IDO1 plays a role in host defense against infection, and its antimicrobial function has been demonstrated for several pathogens, including Toxoplasma gondii, Chlamydia trachomatis, herpes simplex virus type 2 and measles virus (reviewed in [10]). Tryptophan catabolism has also biological significance in pregnancy, since IDO1, which is highly expressed in the placenta, has been shown to protect the fetus from maternal T-cell attack [11]. In addition, disruption of IDO1-mediated tryptophan catabolism exacerbates clinical symptoms and inflammation in several models of autoimmune disease, including experimental autoimmune encephalitis, inflammatory bowel disease, insulin-dependent diabetes mellitus and lupus, highlighting the role of this tryptophan-degrading enzyme in autoimmunity (reviewed in [12]). Interestingly, IDO1 has also been implicated in the induction of tolerance to self-antigens expressed by apoptotic cells, as evidenced by the development of lupus-like pathology and serum autoreactivity to double-stranded DNA in IDO1-deficient mice chronically exposed to apoptotic cells [13]. Finally, there is evidence that IDO1 may be involved in vascular homeostasis, neurological functions and bone remodeling (reviewed in [12]).

In contrast to the plethora of biological functions attributed to IDO1, physiological roles of IDO2 remain largely unknown due to the low activity of this more recently discovered enzyme and the common presence of functionally attenuating IDO2 polymorphisms in the Caucasian population [14]. Although some evidence suggests that IDO2 could support IDO1-mediated immunoregulatory functions [15], IDO2 may also contribute to the development of autoimmune disease, such as rheumatoid arthritis, through promotion of autoantibody production [16].

\section{Arginine-degrading enzymes}

Arginine is an extremely versatile dibasic cationic amino acid that acts as a precursor to essential compounds such as creatine, citrulline, NO, proline and polyamines [17]. It is necessary for protein synthesis, tissue repair and, of most relevance to this review, immune function preservation. Arginine is a semiessential amino acid that can be derived exogenously through diet or endogenously through de novo synthesis or turnover of cellular protein. Although endogenous biosynthesis satisfies cellular metabolic requirements, in cases of nutritional stress or conditions of hyperproliferation (inflammation and cancer) or organ dysfunction (bowel disease and renal disease), dietary intake is required to meet the additional amino acid demands [18]. Arginase catalyzes the hydrolytic conversion of arginine to ornithine and urea. There are two arginase isoforms, ARG1 and ARG2, that catalyze the same chemical reaction, but differ in terms of their regulation, subcellular localization and cellular/ tissue expression. Human ARG1 is a cytosolic enzyme primarily and abundantly found in liver hepatocytes where it plays a crucial role in ammonia detoxification by catalyzing the final part of the urea cycle. It is also constitutively expressed in erythrocytes and in the granules of polymorphonuclear neutrophils from which it is liberated in an inactive form (activated upon extracellular release) during inflammation [19]. ARG1 mRNA expression can be induced by hydrogen peroxide in rat alveolar macrophages, and by lipopolysaccharide or oxidative lipoproteins in murine macrophages, as well as by IL-4, IL-10 and IL-13, the cytokines of the Th2 signature [20]. In fact, this is the characteristic of all murine myeloid populations as granulocytes and DCs also show upregulated ARG1 expression upon Th2 cytokine-mediated stimulation [21]. ARG1 expression is enhanced by IL-21 which causes the upregulation of IL- $4 \mathrm{R} \alpha$ and IL-13R $\alpha$ on the surface of murine macrophages [22], and inhibited by the iNOS intermediate $\mathrm{N}$-hydroxy-L-arginine in line with the antagonistic relationship of these two enzymes which compete for the same substrate [23]. In contrast to ARG1, ARG2 is found in the matrix and outer membrane of mitochondria with a global constitutive expression in various tissues most prominently kidney, prostate, brain, pancreas and small intestine (reviewed in [24]). It is synthesized as a 354-amino acid preprotein and imported to mitochondria via a mitochondrial-specific 
signal peptide where it is processed to the mature form by proteolysis [25]. The regulation of ARG2 is relatively understudied compared with ARG1, but it has been suggested that Toll-like receptor ligands such as lipopolysaccharide and oligodeoxynucleotides containing high amounts of unmethylated cytosine guanine motifs (CpG) induce ARG2 expression in murine macrophages, with dexamethasone and dibutyryl cAMP enhancing this induction [26].

ARG1 plays an important role in the hepatic urea cycle to clear excess toxic nitrogenous waste. ARG1 deficiency in humans also leads to hyperargininemia, low ornithine and excess ammonia with ensuing cirrhosis and neurological disease, justifying why the enzyme is normally constitutively expressed at high levels in the liver [27]. In contrast, ARG2-knockout mice have no obvious phenotype with the exception of elevated levels of arginine and reduced levels of ornithine in blood [28]. Its physiological function is still poorly understood, but evidence suggests that it might regulate arginine concentrations within cells and in the extracellular spaces, and thus controls substrate availability for the biosynthesis of key substances such as $\mathrm{NO}$, proline and polyamines from the arginine precursor [29]. In the vascular endothelium, ARG2 limits arginine availability for endothelial NOS leading to reduced NO and enhanced superoxide production, causing oxidative stress, upregulation of inflammatory and adhesion molecules, such as VCAM-1 and ICAM1, and endothelial dysfunction [30]. Upregulation of arginase prevents iNOS activity, whereas arginase inhibition causes enhanced iNOS expression and leads to increased NO production and ARG-NOS imbalance which is important in the pathophysiology of endothelial dysfunction airway dilatation and asthma and vascular tone [31].

In addition to the metabolic effects mediated by regulation of $\mathrm{NO}$ production, arginase also affects cellular functions through regulation of arginine and ornithine availability for downstream conversion to other amino acids. Ornithine serves as a substrate for both ornithine decarboxylase to produce polyamines, fundamental for cell proliferation, inflammation control and membrane transport, and ornithine aminotransferase to generate proline, the building block of collagen whose synthesis is indispensable for tissue repair and fibrosis (reviewed in [18]). As mentioned earlier, these functions appear to be regulated by the main extrahepatic isoenzyme, ARG2, rather than ARG1 [29].

Another important physiological function of arginase is the modulation of immune responses. However, its role here currently remains ambiguous, as it can lead to both beneficial and detrimental outcomes. First, the competition between arginase and NOS also occurs in macrophages where the former regulates the production of NO from iNOS by limiting the availability of arginine [32]. Alternatively, activated M2 macrophages expand in response to Th2 cytokines such as IL- 4 and IL-13 as well as IL-10 and TGF- $\beta$ to upregulate ARG1, inhibit iNOS and thus enhance humoural immunity, allergic and antihelminth immune responses and also to assist in resolution of inflammation and promotion of tissue repair and healing [33]. This is in contrast to classically activated M1 murine macrophages, which arise as a result of Th1 cytokines such as IFN- $\gamma$ and strongly express iNOS to foster and propagate inflammation [34].

Arginase involvement in autoimmunity can have both positive and negative effects. ARG1 in MDSCs has positive effects through depleting arginine to inhibit T-cell proliferation and resolve inflammation in murine collagen-induced arthritis [35]. In contrast, negative effects have been demonstrated in the CNS where arginase promotes autoimmune inflammation [36] in rheumatoid arthritis where ARG2 upregulation was observed in synovial fluid inflammatory cells [37] and systemic lupus erythematosus where enhanced ARG1 in patient serum leads to arginase-dependent Th17 differentiation and correlates with disease severity [38].

Arginine is crucial during infections as it provides the substrate for generation of NO, which is a strong antimicrobial agent and allows the invaded host cells, especially macrophages, to clear intracellular and extracellular pathogens [39]. This renders the aforementioned competition between arginase and iNOS crucial in deciding the outcome of infections and suggests that arginase activity might tilt the balance in favor of pathogens and lead to poor clinical outcomes [40]. Furthermore, the inevitable arginine deprivation from immune cells and polyamine production might have an equal contribution to this effect. Indeed, it has been demonstrated that the immunomodulatory capacity of pathogen-induced arginase in host cells, primarily macrophages, is detrimental in Salmonella typhimurium, Mycobacterium tuberculosis, Helicobacter pylori, Toxoplasma gondii, Schistosoma mansoni, Trypanosome cruzii or bruceii, Leishmania and even HCV where it promotes the development of $\mathrm{HCV}$-associated hepatocellular carcinoma (reviewed in [40]).

Arginase-mediated arginine depletion is an effective way to keep adaptive immune responses in check. Adequate levels of arginine in the extracellular milieu are crucial for T-cell proliferation and functional $\mathrm{T}$-cell activity [41]. Profoundly, depleted arginine levels in plasma, between 0 and $50 \mu \mathrm{mol} / \mathrm{l}$, are accompanied by loss of $\mathrm{CD} 3 \zeta$ chain expression and T-cell anergy $[42,43]$. In vitro, arginine concentrations below $60 \mu \mathrm{mol} / \mathrm{l}$ decreased $\mathrm{CD} 3 \zeta$ expression, cell proliferation and 
cytokine production [44,45]. Downregulation of CD3, a crucial TCR co-factor, is part of the T-cell inactivation signature that occurs through induction of transcriptional and translational effects regulated by GCN2, a protein that directs the global cellular response to nutritional stress, linking cell proliferation to the abundance of amino acids [46].

Pregnancy is one of the many settings that the immune system needs to be closely regulated. Arginase activity is significantly enhanced in peripheral blood (through release of the enzyme from cells), term placentae of pregnant women and myometrium of pregnant guinea pigs as part of a physiological mechanism to provisionally suppress maternal T-cell function and ensure maternofetal tolerance during pregnancy [43]. Elahi et al. have shown that $\mathrm{CD} 71^{+}$erythrocytes physiologically expand in neonatal mice and human cord blood, and express high amounts of ARG2 that makes them immunosuppressive [47]. Abrogation of the arginase activity of these cells or arginine supplementation restored immune responses and protection against perinatal pathogens such as Listeria monocytogenes and Escherichia coli suggesting a crucial role for ARG2 in neonatal susceptibility to infection.

The regulation of amino acid metabolism is also crucial for antigen presentation [48]. ARG2 is the principal arginase isoenzyme in DCs where it is downregulated by microRNA-155 upon maturation in order for DCs to effectively stimulate T-cell proliferation following antigen presentation [49].

\section{The roles of amino acid degrading enzymes in the tumor microenvironment Tryptophan-degrading enzymes}

In the past decade, tryptophan catabolism has emerged as an important mechanism of cancer immune escape. A significant proportion of human cancers constitutively express IDO1 [3,50], particularly endometrial, cervix, kidney, non-small-cell lung and colorectal carcinomas [3]. The immunosuppressive role of tryptophan catabolism in cancer was revealed in a key study conducted by Benoit Van den Eynde and co-workers. They showed that acquisition of IDO1 by immunogenic tumors prevents their rejection in preimmunized mice through inhibition of tumor-specific $\mathrm{CD} 8^{+} \mathrm{T}$-cell responses [50]. An analogous immunosuppressive effect has been demonstrated in vivo for TDO [9] - another tryptophan catabolizing enzyme that can be hijacked by human tumors, particularly hepatocellular carcinoma and glioblastoma [9,51]. Notably, constitutive TDO expression in glioblastoma not only inhibits tumor-specific $\mathrm{CD} 8{ }^{+} \mathrm{T}$-cell infiltration, but also enhances tumor cell survival and motility in a manner dependent on the activation of the aryl hydrocarbon receptor (AhR) by tryptophan metabolite kynurenine [51]. These findings suggest, for the first time, that kynurenine-dependent AhR activation could be responsible, at least in part, for mediating the immunosuppressive effects of tryptophan-degrading enzymes. In addition to IDO1 and TDO, IDO2 expression has also been detected in some cancers [52]; however, the role of this paralog in tumor immune escape is yet to be determined.

Apart from tumor cells themselves, amino acid degrading enzymes can be expressed by other cells in the tumor microenvironment. IDO1 can be detected in tumor-infiltrating DCs and macrophages, as well as DCs in tumor-draining lymph nodes (TDLNs), as has been observed in patients with malignant melanoma and breast carcinoma [5,53]. Notably, such IDO1-competent DCs exhibit immunosuppressive properties [53,54]. IDO1 can also be expressed by mesenchymal stem cells in the tumor microenvironment, which are able to suppress antitumor T-cell responses and promote tumor growth in a manner dependent on IDO1-mediated tryptophan catabolism [55]. This IDO1 upregulation in tumor-associated cells is of great importance, as it may contribute to the tumor-induced tolerance in the local microenvironment.

Importantly, IDO1 expression is associated with poor clinical prognosis in several human cancers and typically correlates with decreased survival, for example, in melanoma, colorectal, endometrial, ovarian and non-small-cell lung carcinomas (reviewed in [56]) and childhood acute myeloid leukemia (AML) [57]. Furthermore, in some cancers, such as colorectal, endometrial and breast cancers, IDO1 expression correlates with increased risk of metastasis [56], which points to its active contribution to tumor progression. The association between TDO expression and clinical parameters in cancer has not been examined in as much detail yet; however, there is evidence of decreased survival of patients with TDO-expressing gliomas [51].

A key question regarding amino acid degrading enzyme dysregulation in cancer is the nature of the molecular signaling events and stimuli controlling their expression in the tumor microenvironment. Evidence suggests that these factors can be intrinsic to both the tumor and host immune cells. One cause of IDO1 upregulation in tumor cells is the loss of the tumor-suppressor gene Binl, which acts as a negative regulator of $I D O 1$ expression [58]. IDO1 expression in tumors can also be driven by cancer-specific signaling pathways, such as the constitutively activated oncogenic KIT-PI3K-AKT pathway in gastrointestinal stromal tumors [59], as well as PGE2 [60,61] and IFN- $\gamma$, which is produced by tumor-infiltrating $T$ cells [62]. Importantly, tumor immune escape can be intrinsically driven by the immune system, as it has been dem- 
onstrated that IDO1 induction in melanoma is a consequence of the immune pressure imposed on tumor cells by $\mathrm{CD} 8^{+} \mathrm{T}$ cells [62].

There is a growing body of evidence indicating that IDO1 and TDO expressions in the tumor microenvironment lead to induction of localized immune tolerance, which provides the tumor with a selective growth advantage $[9,50,51,55,58]$. IDO1- and TDOmediated tryptophan catabolism may contribute to tumor-induced tolerance through multiple mechanisms (Figure 1). One important aspect of immune regulation by IDO1 is inhibition of T-cell proliferation. In T cells, IDO1-mediated tryptophan depletion induces a proliferative arrest, inhibiting the G1-to-S phase transition [4,63-65]. Specifically, this occurs when tryptophan concentrations drop below $5 \mu \mathrm{M}$ [64]. GCN2 kinase, directly activated by uncharged tRNA, the levels of which increase upon amino acid starvation, is instrumental for the execution of tryptophan shortage-induced T-cell proliferative arrest, as $\mathrm{T}$ cells from $\mathrm{GCN} 2^{-/-}$mice remain resistant to IDO1-mediated suppression and continue to proliferate even in the presence of IDO1-competent pDCs [65]. The inhibitory effect of IDO1- and TDO-mediated tryptophan catabolism on tumor-specific CD8 ${ }^{+}$T-cell infiltration has also been demonstrated in various tumor models in vivo, and can be reversed by pharmacological inhibition of IDO1 or TDO $[9,50,51,55]$.

Tryptophan metabolites, including kynurenine, 3-hydroxykynurenine, 3-hydroxyanthranilic acid and quinolinic acid, have also been shown to exhibit immunosuppressive properties, particularly induction of apoptosis in activated T cells and NK cells [66,67]. Interestingly, such a cytotoxic action appears to be selective to certain T-cell subsets. The 3-hydroxyanthranilic acid and quinolinic acid, for example, induce cell death in Th1, but not in Th2, cells [66]. Consistently, administration of tryptophan metabolites in vivo induces selective depletion of specific immune cell subsets [66]. The molecular mechanisms mediating this selective cytotoxicity are not fully understood, but may involve caspase- 8 activity [66] and glutathione depletion [67]. There is also evidence that tryptophan metabolites may synergize with tryptophan depletion in the induction of some immunosuppressive effects, for example, TCR $\zeta$-chain downregulation and the associated reduction in effector T-cell cytotoxic function [46]. Finally, IDO1-catalyzed tryptophan metabolism may hamper antitumor effector T-cell responses by inducing anergy [53,65], suppressing T-cell activation through disruption of calcium signaling [68] and interfering with T-cell metabolism, namely inhibiting glucose uptake, aerobic glycolysis and glutaminolysis [69].
Although there is compelling evidence demonstrating that IDO1- and TDO-dependent catabolism inhibits tumor-specific immune responses, it remains largely unclear how tumor cells themselves are able to withstand the effects of local tryptophan depletion. We have recently addressed this question by performing RNAseq analysis of IDO1-expressing tumor cells, which revealed extensive remodeling of tumor cell metabolism, amino acid biosynthesis and amino acid transport gene expression by tryptophan catabolism. In particular, our findings demonstrated that IDO1 or TDO expression in tumor cells induces ATF4-dependent upregulation of several amino acid transporter genes, including SLC1A5 and its truncated isoforms, which allows improved glutamine and tryptophan import into tumor cells. Importantly, this strategy is not shared by human $\mathrm{T}$ cells, which provides important insights into the mechanisms by which cancer cells but not tumor-infiltrating $T$ cells can compensate for the shortage of tryptophan in the local microenvironment [70].

In contrast to the inhibitory effects of tryptophan catabolism on effector T-cell responses, IDO1 activity strongly promotes Treg cell differentiation and function. Both pDCs and monocyte-derived DCs expressing IDO1 have been shown to induce Treg cells [71]. Tryptophan deficiency, in synergy with tryptophan metabolites, is also able to trigger conversion of naive $\mathrm{CD}^{+} \mathrm{CD} 25^{-} \mathrm{T}$ cells into a regulatory phenotype [46]. Furthermore, IDO1 expression in human tumors often correlates with the increased number of Treg cells, for example, in AML, non-Hodgkin lymphoma and melanoma [62,72,73]. Evidence exists that such a bias toward a Treg cell phenotype is tumor driven. In line with this concept, exposure of $\mathrm{CD} 4^{+} \mathrm{CD} 25^{-} \mathrm{T}$ cells to tumor cell conditioned medium is able to induce Treg cell generation [72]. Moreover, AML cells and leukemic DCs that express IDO1 can directly promote Treg cell conversion, generating Treg cells capable of suppressing leukemia-specific effector T-cell responses. Treg cell conversion in this system is dependent on IDO1, as it can be suppressed by pharmacological inhibition of the enzyme [57,72,74]. Acquisition of the regulatory phenotype by naive $\mathrm{CD} 4^{+} \mathrm{CD} 25^{-} \mathrm{T}$ cells under low tryptophan conditions is thought to depend on TGF $\beta$ mediated induction of the forkhead transcription factor (Foxp3) [46,75] and GCN2 activation [46], although there is some evidence that inhibition of mTOR signaling may also be involved [75]. In addition to tryptophan depletion, Treg cell generation can be induced by AhR activation by kynurenine [76], revealing another molecular mechanism employed by IDO1 to signal for a Treg cell phenotype. Finally, the ability of tumorderived IDO1 to increase Treg cell numbers has been confirmed in mouse tumor models in vivo [72]. 


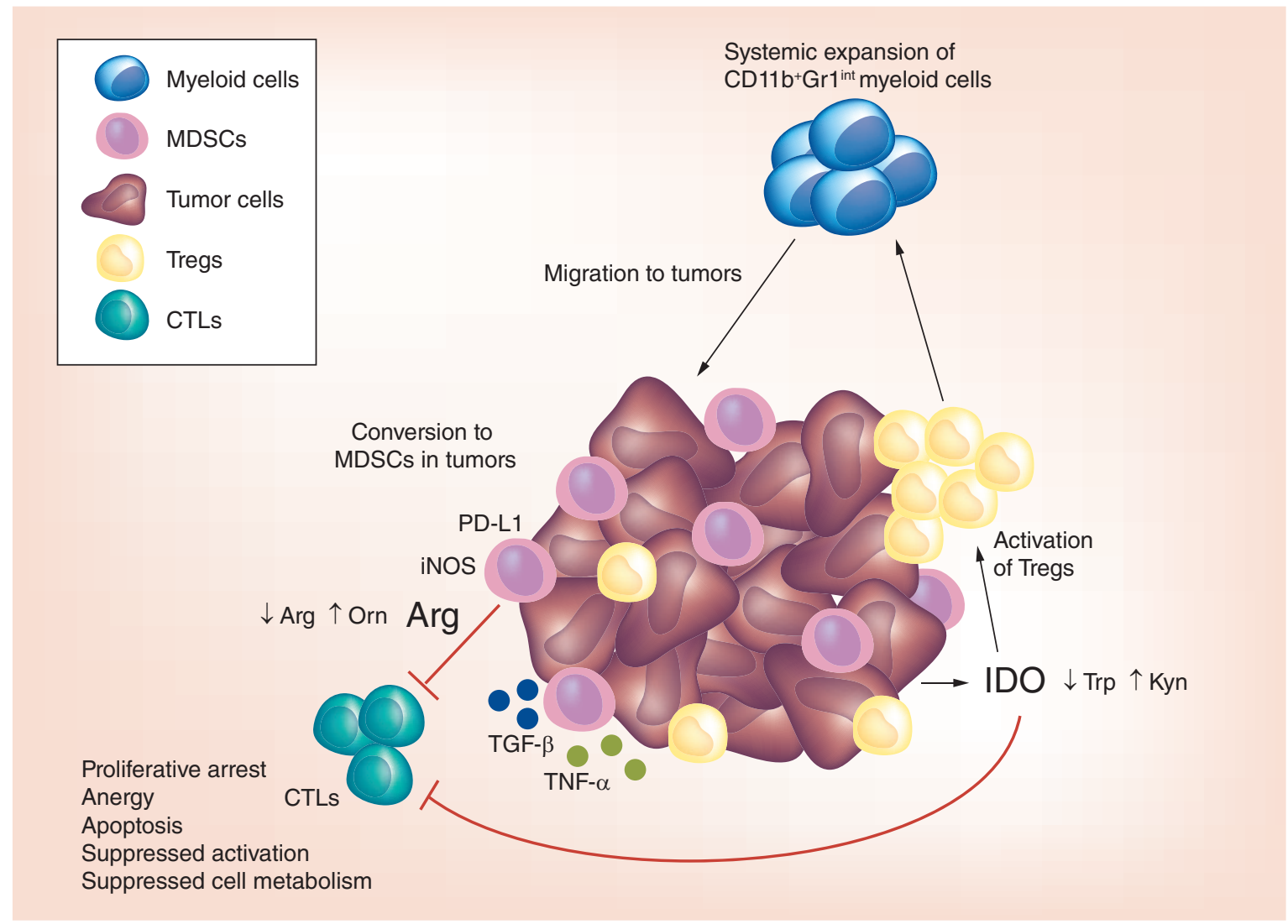

Figure 1. Modulation of cancer-specific responses by amino acid degradation in the tumor

microenvironment.Tryptophan and arginine catabolism in the tumor microenvironment can hamper the antitumor immune response through multiple mechanisms, including the induction of tumor-infiltrating CTL proliferative arrest, anergy and apoptosis, interference with optimal CTL activation and metabolic function. IDO1-mediated tryptophan degradation is also able to promote Treg cell differentiation and activation, which, in turn, leads to the expansion and intratumoral recruitment of ARG-competent immunosuppressive myeloid populations like MDSCs. MDSCs can then further inhibit antitumor effector T-cell responses through arginase-, iNOS-, PD-L1- and inhibitory cytokine-dependent mechanisms. Thus, tryptophan- and arginine-degrading enzymes can cooperate together to establish complex immunosuppressive networks in the tumor microenvironment.

ARG: Arginase; CTL: Cytotoxic T lymphocyte; IDO1: Indoleamine 2,3-dioxygenase 1; iNOS: Inducible nitric oxide synthase; MDSC: Myeloid-derived suppressor cell.

Modified with permission from [80] @) Elsevier (2015).

In addition to de novo generation of Treg cells [71], IDO1-expressing pDCs in TDLNs are able to activate pre-existing Treg cells and enhance their suppressor function in an IDO1-, GCN2- or CTLA-4-dependent manner [53,54]. Such IDO1-induced Treg cells appear to utilize the PD-1/PD-L1 pathway for immunosuppression [54]. IDO1-competent pDCs also contribute to the maintenance of a stable Treg cell phenotype, limiting Treg cell plasticity and preventing their conversion into proinflammatory Th17 cells through GCN2-dependent inhibition of IL-6 production [77]. In turn, Treg cells induce IDO1 expression in DCs by initiating CTLA-4 interaction with DC costimulatory molecules B7-1/B7-2. CTLA-4 ligation triggers reverse signaling by $\mathrm{B} 7-1 /-\mathrm{B} 7-2$, leading to IFN- $\gamma-$ and STAT1dependent IDO1 production $[7,8]$. Upregulation of IDO1 can also be achieved by direct cross-linking of
B7-1/-B7-2 molecules on DCs through administration of soluble fusion protein CTLA-4-immunoglobulin, which promotes tolerance in vivo [7]. In addition to CTLA-4-dependent mechanisms, expression of IDO1 in DCs can be self-amplified through IDO1 enzymatic activity-independent immune signaling triggered by TGF- $\beta$ [78], of which Treg cells are major producers. Of note, the signaling activity of IDO1 protein, mediated by immunoreceptor tyrosine-based inhibitory motifs, has been shown to promote the tolerogenic properties of DCs [78,79], and thus may further contribute to tumor-induced immune tolerance.

The bias toward the Treg cell phenotype in IDO1expressing tumors is of importance not only due to the inhibitory function of these cells, but also due to their potential to amplify the immunosuppressive network in the tumor microenvironment. Treg cells can achieve 
this by imposing tolerogenic properties on DCs through induction of IDO1, as discussed above, as well as by recruiting and activating other immunosuppressive cell populations, such as MDSCs, which can suppress antitumor effector T-cell responses through ARG1 and iNOS activities and generation of immunosuppressive cytokines (Figure 1) [80]. Importantly, inhibiting IDO activity or depleting FoxP3 ${ }^{+}$Treg cells prevents MDSC infiltration in human melanoma, releasing immunosuppression and delaying tumor growth [80], which highlights the central role of IDO in the regulation of tumor-induced immune tolerance.

Notably, the immunosuppressive effects of IDO1 are not limited to $\alpha \beta$ T cells. IDO1 activity has been reported to restrict $\gamma \delta$ T-cell reactivity [81], modulate cytokine responses by invariant natural killer $\mathrm{T}$ (iNKT) cells, favoring Th2-type cytokines IL-4 and IL-13 over proinflammatory IFN- $\gamma$ [82], promote macrophage polarization toward the anti-inflammatory M2 phenotype [83] and inhibit NK cell cytolytic function through downregulation of specific activating receptors [84]. IDO1 expression in melanoma has also been shown to hamper NK-cell-mediated antitumor immunity [84]. Others, however, argue that IDO1 is required for NK cell antitumor response [85]. Further research is required to resolve these discrepancies.

In summary, there is a growing body of evidence demonstrating the immunosuppressive role of tryptophan-degrading enzymes in the tumor microenvironment. Immunoregulation by tryptophan catabolism involves several pathways, including GCN2 and AhR, and affects diverse aspects of the antitumor immune response, ranging from tolerogenic status of APCs to viability, differentiation and function of $\mathrm{T}$ cells.

\section{Arginine-degrading enzymes}

The presence of arginase in the tumor microenvironment can have a variety of detrimental effects: inhibition of tumoricidal NO production by inflammatory macrophages, generation of polyamines (via ornithine) that support cancer cell proliferation and local arginine depletion within the tumor microenvironment or systemically, causing T-cell dysfunction and immunosuppression [86]. Arginine deprivation is now a recognized strategy for cancer cells to keep antitumor lymphocyte responses in check (Figure 1). Therefore, it is no surprise that arginase expression has been demonstrated in many cancer cell lines including non-small-cell lung cancer, colorectal cancer, breast cancer, prostate cancer and renal cell carcinoma (RCC) [86-91]. Tumor arginase deprives arginine from immune cells within the local tumor microenvironment rendering them dysfunctional. In prostate cancer, ARG2 (and iNOS) expression is aberrantly high, suppressing tumor-infiltrating lymphocytes that can be reversed through pharmacological inhibition of the two enzymes [92]. ARG2 expression is further enhanced by androgens, explaining why androgen depletion therapy, which diminishes ARG2 activity, is often followed by an immunological boost (i.e., enhanced T-cell activation and IFN- $\gamma$ secretion) in vivo, a result that mirrors the effects of arginase knockdown in prostate cancer cells in vitro [87]. Arginase activity is also enhanced in gastric cancer when compared with healthy gastric tissue [93] and the enzyme is released in vitro by gastric cancer cell lines and in the serum of patients with gastric cancer [94]. Arginase activity, attributed to ARG2 levels, was significantly higher in breast cancer tissue as well as in peripheral blood of breast cancer patients compared with healthy donors [95].

In addition to direct amino acid degradation by the cancer cells, tumors are also able to hijack surrounding stromal cells or incoming immune cells, such as TAMs and MDSCs rendering them immunosuppressive (Figure 1). Among other actions, these cancer-associated cells overexpress and secrete arginase to deplete arginine in the microenvironment and provide one of the main mechanisms of inducing T-cell anergy and facilitating cancer immune evasion [96].

MDSCs are immature monocytes or granulocytes found in bone marrow. However, they frequently expand within solid tumors, and in the spleen, lymph nodes and peripheral blood of human cancer patients, and in cancer mouse models. MDSCs suppress T-cell function and promote cancer spread leading to poor clinical outcomes [97-99]. They impair immune responses in a number of ways including production of reactive nitrogen and oxygen species, which appears to require ARG1 expression to deplete arginine followed by iNOS expression [100]. The most recognized mechanism is through arginase- and iNOS-mediated arginine depletion [101]. ARG1 expression can be induced by various tumor-released soluble factors such as prostaglandins (synthesized as a result of COX-2 overexpression in tumors) or via activation of the transcription factors STAT3 [102] and STAT6 [103]. This generates an arginine-depleted microenvironment that starves $T$ cells and prevents their activation and proliferation [104]. In ovarian cancer, expansion of a population of vascular leukocytes that have MDSClike phenotype and express ARG1 has been reported in the peritoneum of both humans and mice [105]. These vascular leukocytes had the ability to suppress CD4 and CD8 T-cell proliferation, an effect that was alleviated by specifically blocking ARG1 activity, explaining why selective depletion of vascular lymphocytes in the ID8 murine ovarian cancer model leads to reduced tumor burden [105]. In addition to their direct effects 
on T cells through arginine depletion, MDSCs further promote the creation of an immunosuppressive tumor microenvironment through their capacity to expand Treg by a mechanism that depends on their expression of ARG1 as well as uptake and presentation of tumor antigens to Treg via MHC class II molecules [106].

Enhanced ARG1 activity in peripheral blood as a result of the expansion of MDSC has been demonstrated in RCC [107], breast cancer [108] and head and neck squamous cell carcinomas (within TDLNs and peripheral blood) [102]. In addition to their intracellular arginase activity, MDSCs also store ARG1 in granules that can be released in the extracellular space to directly deplete arginine in the microenvironment [109]. Indeed, Ochoa and colleagues demonstrated that the release of ARG1 in the plasma of RCC patients reduced systemic arginine levels below the threshold required for T-cell proliferation [110]. We have recently shown that circulating AML blasts are phenotypically similar to MDSCs and are able to express and release ARG2 (rather than ARG1) in peripheral blood [111]. The high levels of circulating ARG2 inhibit not only T-cell proliferation but also proliferation of hematopoietic progenitor and stem cells and additionally polarize monocytes toward expanding into an ARG1-expressing, immunosuppressive M2 population [111]. These findings were confirmed in vivo using AML murine xenografts. Notably, these immunosuppressive effects were almost completely abrogated with use of small molecule arginase inhibitors. This suggests that ARG2 is a promising target to boost tumor-specific immune responses or in combination with other immunotherapies and address the general state of immunosuppression and pancytopenia seen in the context of AML.

TAMs comprise a significant proportion of the expanding tumor and correlate with poor clinical outcomes [112]. This is due in part to the capacity of M2-polarized TAMs to promote tumor angiogenesis, invasion and metastasis. However, TAMs also display high ARG1 activity, which leads to depletion of arginine in the tumor microenvironment, thereby interfering with TCR signaling, suppressing T-cell activation and proliferation to escape the antitumor immune response [104,113]. Overexpression of ARG1 in M2 macrophages within the tumor microenvironment has been shown to promote tumor growth in prostate, lung and renal carcinomas $[104,110,114]$. Consistent with a prominent role for TAMs and MDSCs in assisting immune-mediated evasion of cancer, inhibition of ARG1 blocked the growth of lung carcinoma in mice suggesting that arginase is an attractive therapeutic target to boost anticancer immune responses [104]. Nevertheless, immunosuppression, through arginine depletion, is not the only way that TAM-expressing arginase can promote tumor growth. Macrophage arginase activity has been reported to be important in angiogenesis and cancer cell proliferation, both most likely as a polyamine generation following arginine conversion to ornithine [86]. Furthermore, a temporal relationship between macrophage ARG1 and NOS expressions has also been suggested to be crucial for immunosuppression. Ochoa et al. proposed that ARG1 expression occurs initially to induce T-cell tolerance via interference with TCR signaling and cell cycle arrest; this is then followed by NOS expression that promotes NO-associated apoptosis further inhibiting any anticancer immune responses [115]. This temporal pattern might also relate to the tumor development as expression of ARG1, but not iNOS, was detectable in pulmonary macrophages of mice carrying premalignant lung lesions (induced by urethane) whereas the same cell population expressed iNOS but not ARG1 in mice with lung carcinomas [116].

More recently, ARG2 expression was demonstrated in cancer-associated fibroblasts in the context of the hypoxic environment of pancreatic cancer [117]. The presence of ARG2-expressing cancer-associated fibroblasts correlated with poor overall and disease-free survival in patients and suggests that tumor-associated stromal cells are key players in the immune regulation of the tumor microenvironment.

\section{Future perspective}

Therapeutic targeting of tryptophandegrading enzymes

The key role of amino acid degrading enzymes in the regulation of tumor-induced immune tolerance makes them promising therapeutic targets. The immunosuppressive tryptophan catabolism in cancer can be targeted therapeutically on multiple levels. One approach is to disrupt the enzymatic activity of IDO. Numerous IDO-targeted inhibitors have shown promising results in preclinical animal studies, including melanoma, breast, brain, pancreatic and colon cancers [118-120]. IDO represents a particularly attractive target for cancer immunotherapy due to its well-studied biochemistry (reviewed in [12]), resolved crystal structure [121] and lack of autoimmune disease observed in IDOI knockout mice [122], predictive of minimal side effects induced by pharmacological IDO1 blockade. The first IDO inhibitor, 1-methyl-tryptophan (1-MT), showed best efficacy in tumor rejection when used in combination with chemotherapy $[58,118,120]$, and has also been reported to synergize with anti-CTLA-4 immunotherapy in vivo [123]. Two racemic isoforms of 1-MT exist $-1-_{-}-M T$ and $11_{D}-M T$. While $1-_{-}-M T$ has proved more potent at inhibiting the activity of the purified IDO1 enzyme, $1_{-}$-MT has demonstrated higher anti- 
tumor efficacy in immune cell-based assays in vitro and in tumor models in vivo, compared with $1_{-}-\mathrm{MT}$ [18]. Notably, $1_{\mathrm{D}}-\mathrm{MT}$, but not 1- $-\mathrm{MT}$, has also been shown to target the IDO2 paralog in addition to IDO1 [14]. Several IDO inhibitors are currently undergoing Phase I/II clinical trials in humans, including 1- $-\mathrm{MT}$ (also referred to as indoximod or NLG8189). Indoximod has completed the first small-scale Phase I clinical trial, showing no substantive toxicity and some antitumor activity in combination with chemotherapy in patients with metastatic solid tumors [124]. Future efforts will be directed toward evaluating the efficacy and safety of indoximod in combination with other therapies, such as the CTLA-4-targeting drug ipilimumab [125] and anticancer vaccines [126]. Another promising clinical candidate is the second-generation IDO inhibitor epacadostat (also referred to as hydroxyamidine or INCB024360), which has shown efficacy in pancreatic and colon tumor models [119], and is currently being evaluated in several Phase I/II combination drug trials, including its combination with anti-CTLA- 4 immunotherapy in metastatic melanoma [127].

An alternative strategy to disrupt the IDO1-dependent immunosuppressive network is to target the molecular signaling events regulating IDO1 expression in the tumor microenvironment. One successful example of such an approach is the tyrosine kinase inhibitor imatinib, which has been shown to suppress IDO1 expression through inhibition of oncogenic KIT signaling [59]. Interestingly, the antitumor effects of imatinib in gastrointestinal stromal tumors have been attributed, at least in part, to the downregulation of tumor-derived IDO1 expression [59]. Furthermore, IDO1 induction in the tumor microenvironment can be prevented through inhibition of COX-2 activity an enzyme key for the production of PGE2, which is capable of inducing IDO1 expression [6,61]. Quite promisingly, early pre-clinical studies have demonstrated that COX-2 inhibition is able to reduce the levels of IDO1, suppress tumor growth and metastasis and improve the antitumor efficacy of a DC-based cancer vaccine $[60,128]$. In addition, COX-2 inhibition has been shown to suppress the IDO1-mediated de novo conversion of Treg cells by AML cells [129]. Further studies exploring inhibition of COX-2 in the context of IDO1-mediated immunosuppression are warranted; however, the potential side effects of such therapy, including the increased risk of cardiac toxicity [130], have to be carefully considered. Notably, therapeutic targeting of the upstream pathways controlling IDO1 expression represents an important area of research, as, in addition to IDO1 enzymatic activity, it could be used to block IDO1 nonenzymatic immune signaling, which has been shown to promote immune tolerance $[78,79]$ and is likely to be refractory to IDO1 enzymatic inhibitors. IDO1 signaling activity could also be inhibited directly, for example, by targeting Fyn-mediated IDO1 immunoreceptor tyrosine-based inhibitory motif phosphorylation or recruitment of Src homology 2 domain-containing protein tyrosine phosphatase (SHP) tyrosine phosphatases [78]. Moreover, recent findings describe natural T-cell responses against tryptophan-degrading enzymes themselves (IDO1, IDO2 and TDO) (reviewed in [131]), which raises an interesting possibility of vaccinating cancer patients against IDO/TDO-derived peptides to promote the immune-mediated clearance of pathogenic IDO/TDO-competent cells - an approach that is already being tested in clinical trials $[132,133]$.

Dissecting the compensatory mechanisms employed by IDO- and TDO-expressing tumors to survive under low tryptophan conditions may also provide promising therapeutic avenues. The emerging evidence suggests that tumor cells expressing tryptophandegrading enzymes can compensate for the shortage of tryptophan in the local microenvironment by upregulating cellular tryptophan uptake [63,70]. Such tryptophan transport pathways could prove to be important therapeutic targets, and further research is needed to explore this possibility. Another relatively unexplored avenue of considerable interest is therapeutic targeting of the tryptophan catabolism-sensing pathways GCN2 and AhR, which have been shown to mediate several immunosuppressive effects of IDO and TDO. Future efforts will be directed toward dissecting the promiscuity and complexity of these signaling pathways, which may provide new strategies for cancer immunotherapy.

\section{Therapeutic targeting of arginine-degrading enzymes}

Modulation of the immunosuppressive, tumor-promoting activity of MDSCs or TAMs through global depletion or specific targeting of arginase could clearly have significant therapeutic implications. Various reports have shown that antibody-mediated chelating of MDSCs allowed CD8 T cells to mount antitumor responses [134]. Addition of small-molecule arginase inhibitors such as nor-N-hydroxy-L-arginine abrogated the arresting effects of arginase on T-cell proliferation and allowed lymphocyte-dependent tumor reduction [104]. More recently, results for a novel arginase-specific inhibitor were released showing that the drug had a significant immune-mediated antitumor effect [135]. The combination of arginase inhibitor with checkpoint inhibitors (anti-PD-1 and anti-CTLA-4) in mice bearing Lewis lung carcinoma led to decrease in tumor growth and an enhancement in tumor infiltrating cytotoxic lymphocytes and an increase in 
Th1-associated cytokines within the tumor microenvironment. Treatment had no effects in immunocompromised mice highlighting that the mechanism by which arginase inhibitors exert antitumor effects involves the immune system.

Another potential combination therapy is that of radiation treatment with arginase inhibition. Recent evidence supports the notion that the suppression of adaptive immune responses generated postradiotherapy is, at least, partially due to ARG1 expression in MDSC and in line with this, deletion of ARG1 in the myeloid compartment of tumor-bearing mice improved tumor control after radiation [136].

As MDSCs are also able to polarize macrophages toward the M2 phenotype, at least partially through ARG1 activity, arginase inhibitors could have a double effect in favor of T cells by preventing the expansion of immunosuppressive TAMs [111]. Furthermore, as arginase leads to accumulation of ornithine, the precursor of polyamines, which facilitate cancer cell proliferation, abrogation of the enzyme's activity could also lead to additional bystander effects detrimental to the tumor. In line with the latter, difluoromethylornithine, an inhibitor of ornithine decarboxylase, the enzyme that catalyzes polyamine synthesis from ornithine, has demonstrated promising antitumor effects in mouse models of prostate cancer [137]. Finally, phosphodiesterase-5 inhibition, acting by downregulating ARG1 and iNOS expressions in MDSC, alleviated the suppression of stimulated T-cell proliferation in patients with multiple myeloma or head and neck cancers and also improved the infiltration of activated $\mathrm{T}$ cells within tumors leading to diminished tumor growth [138].

In the case of circulating arginase, monoclonal antibodies that would specifically bind one of the two isoenzymes, depending on which is most prominent in each context (e.g., ARG2 in AML), could theoretically provide a strong alternative to small-molecule inhibitors, with their increased specificity, enhanced bioavailability and reduced toxicity [109-111,139].

All in all, pharmacological inhibition of arginase would promote the generation of an inflammatory tumor microenvironment as opposed to an immunosuppressive tumor microenvironment that would favor cancer-specific immune responses against cancer cells. It is likely that arginase inhibitors would form part of combination immuno-oncology therapies perhaps alongside checkpoint inhibitors such as anti-PD-1 and anti-CTLA-4 playing a critical role in boosting the cytotoxic CD8 T-cell response against tumors.

\section{Executive summary}

\section{Diverse mechanisms of tumor immune evasion}

- Tumors evade immune destruction using a wide range of strategies that target several aspects of the antitumor immune response, as well as exploit host immunosuppressive mechanisms. It has become evident that the expression of tryptophan- and arginine-degrading enzymes by tumor and tumor-infiltrating cells plays a key role in the immunosuppressive tumor microenvironment.

Amino acid degrading enzymes \& their physiological roles

- Tryptophan-degrading enzymes indoleamine 2,3-dioxygenase (IDO) and tryptophan 2,3-dioxygenase (TDO), and arginine-degrading enzymes arginase 1 (ARG1) and arginase 2 (ARG2) are expressed in various tissues and play diverse physiological roles, including metabolic regulation of the immune response in infection, pregnancy and autoimmunity.

The roles of amino acid degrading enzymes in the tumor microenvironment

- IDO and TDO expressions by tumor cells and tumor-associated dendritic cells, macrophages and mesenchymal stem cells can hamper cancer-specific immune responses through multiple mechanisms, including inhibition of tumor-specific T-cell infiltration, induction of T-cell proliferative arrest, anergy and apoptosis, as well as promotion of Treg cell differentiation and function.

- ARG1 is expressed by myeloid-derived suppressor cells, tumor-associated macrophages and tumor cells, whereas ARG2 is expressed by various solid tumor cells, acute myeloid leukemia blasts and cancer-associated stromal cells, such as fibroblasts. Arginase expression in the tumor microenvironment dampens cancerspecific immune responses through local and in certain contexts systemic suppression of T-cell proliferation, inhibition of T-cell activation and promotion of T-cell anergy and apoptosis, as well as through macrophage reprogramming that promotes immunosuppressive phenotypes.

Future perspective

- There is a promising potential in targeting the immunosuppressive tryptophan and arginine catabolism in cancer. While the development of therapeutics aimed at inhibition of IDO and arginase enzymatic activity and induction stimuli is underway, future efforts will attempt to shed light on the promiscuity and complexity of amino acid catabolism-sensing pathways and the compensatory mechanisms employed by IDO-, TDO- and arginase-expressing tumors to allow survival under conditions of nutritional stress, which could provide new strategies for cancer immunotherapy. 


\section{Financial \& competing interests disclosure}

The authors have no relevant affiliations or financial involvement with any organization or entity with a financial interest in or financial conflict with the subject matter or materials discussed in the manuscript. This includes employment, consultancies, honoraria, stock ownership or options, expert testimony, grants or patents received or pending, or royalties.

No writing assistance was utilized in the production of this manuscript.

\section{Open access}

This work is licensed under the Attribution-NonCommercialNoDerivatives 4.0 Unported License. To view a copy of this license, visit http://creativecommons.org/licenses/by-nc$\mathrm{nd} / 4.0 /$

\section{References}

1 Rabinovich GA, Gabrilovich D, Sotomayor EM. Immunosuppressive strategies that are mediated by tumor cells. Annu. Rev. Immunol. 25, 267-296 (2007).

2 Zou WP. Immunosuppressive networks in the tumour environment and their therapeutic relevance. Nat. Rev. Cancer 5(4), 263-274 (2005).

3 Theate I, Van Baren N, Pilotte L et al. Extensive profiling of the expression of the indoleamine 2,3-dioxygenase 1 protein in normal and tumoral human tissues. Cancer Immunol. Res. 3(2), 161-172 (2015).

4 Munn DH, Shafizadeh E, Attwood JT, Bondarev I, Pashine A, Mellor AL. Inhibition of T cell proliferation by macrophage tryptophan catabolism. J. Exp. Med. 189(9), 1363-1372 (1999).

5 Munn DH, Sharma MD, Lee JR et al. Potential regulatory function of human dendritic cells expressing indoleamine 2,3-dioxygenase. Science 297(5588), 1867-1870 (2002).

6 Braun D, Longman RS, Albert ML. A two-step induction of indoleamine 2,3 dioxygenase (IDO) activity during dendritic-cell maturation. Blood 106(7), 2375-2381 (2005).

7 Grohmann U, Orabona C, Fallarino F et al. CTLA-4-Ig regulates tryptophan catabolism in vivo. Nat. Immunol. 3(11), 1097-1101 (2002).

8 Fallarino F, Grohmann U, Hwang KW et al. Modulation of tryptophan catabolism by regulatory T cells. Nat. Immunol. 4(12), 1206-1212 (2003).

9 Pilotte L, Larrieu P, Stroobant V et al. Reversal of tumoral immune resistance by inhibition of tryptophan 2,3-dioxygenase. Proc. Natl Acad. Sci. USA 109(7), 2497-2502 (2012).

10 Schmidt SV, Schultze JL. New insights into IDO biology in bacterial and viral infections. Front. Immunol. 5, 384 (2014).

11 Munn DH, Zhou M, Attwood JT et al. Prevention of allogeneic fetal rejection by tryptophan catabolism. Science 281(5380), 1191-1193 (1998).

12 Yeung AW, Terentis AC, King NJ, Thomas SR. Role of indoleamine 2,3-dioxygenase in health and disease. Clin. Sci. (Lond.) 129(7), 601-672 (2015).
13 Ravishankar B, Liu HY, Shinde R et al. Tolerance to apoptotic cells is regulated by indoleamine 2,3-dioxygenase. Proc. Natl Acad. Sci. USA 109(10), 3909-3914 (2012).

14 Metz R, Duhadaway JB, Kamasani U, Laury-Kleintop L, Muller AJ, Prendergast GC. Novel tryptophan catabolic enzyme IDO2 is the preferred biochemical target of the antitumor indoleamine 2,3-dioxygenase inhibitory compound D-1-methyl-tryptophan. Cancer Res. 67(15), 7082-7087 (2007).

15 Metz R, Smith C, Duhadaway JB et al. IDO2 is critical for IDO1-mediated T-cell regulation and exerts a non-redundant function in inflammation. Int. Immunol. 26(7), 357-367 (2014).

16 Merlo LMF, Pigott E, Duhadaway JB et al. IDO2 is a critical mediator of autoantibody production and inflammatory pathogenesis in a mouse model of autoimmune arthritis. J. Immunol. 192(5), 2082-2090 (2014).

17 Morris SM Jr. Arginine: beyond protein. Am. J. Clin. Nutr. 83(2), s508-s512 (2006).

18 Wu G, Morris SM Jr. Arginine metabolism: nitric oxide and beyond. Biochem. J. 336(Pt 1), 1-17 (1998).

19 Kim PS, Iyer RK, Lu KV et al. Expression of the liver form of arginase in erythrocytes. Mol. Genet. Metab. 76(2), 100-110 (2002).

20 Modolell M, Corraliza IM, Link F, Soler G, Eichmann K. Reciprocal regulation of the nitric oxide synthase/arginase balance in mouse bone marrow-derived macrophages by TH1 and TH2 cytokines. Eur. J. Immunol. 25(4), 1101-1104 (1995).

21 Mayer AK, Bartz H, Fey F, Schmidt LM, Dalpke AH. Airway epithelial cells modify immune responses by inducing an anti-inflammatory microenvironment. Eur. J. Immunol. 38(6), 1689-1699 (2008).

22 Pesce J, Kaviratne M, Ramalingam TR et al. The IL-21 receptor augments Th2 effector function and alternative macrophage activation. J. Clin. Invest. 116(7), 2044-2055 (2006).

23 Boucher JL, Custot J, Vadon S et al. N omega-hydroxyl-Larginine, an intermediate in the $\mathrm{L}$-arginine to nitric oxide pathway, is a strong inhibitor of liver and macrophage arginase. Biochem. Biophys. Res. Commun. 203(3), 1614-1621 (1994).

24 Mori M. Regulation of nitric oxide synthesis and apoptosis by arginase and arginine recycling. J. Nutr. 137(6 Suppl 2), s1616-s1620 (2007).

25 Vockley JG, Jenkinson CP, Shukla H, Kern RM, Grody WW, Cederbaum SD. Cloning and characterization of the human type II arginase gene. Genomics 38(2), 118-123 (1996).

26 Gotoh T, Sonoki T, Nagasaki A, Terada K, Takiguchi M, Mori M. Molecular cloning of cDNA for nonhepatic mitochondrial arginase (arginase II) and comparison of its induction with nitric oxide synthase in a murine macrophage-like cell line. FEBS Lett. 395(2-3), 119-122 (1996).

27 Crombez EA, Cederbaum SD. Hyperargininemia due to liver arginase deficiency. Mol. Genet. Metab. 84(3), 243-251 
(2005).

28 Deignan JL, Livesay JC, Yoo PK et al. Ornithine deficiency in the arginase double knockout mouse. Mol. Genet. Metab. 89(1-2), 87-96 (2006).

29 Iyer RK, Bando JM, Jenkinson CP et al. Cloning and characterization of the mouse and rat type II arginase genes. Mol. Genet. Metab. 63(3), 168-175 (1998).

30 Xia Y, Dawson VL, Dawson TM, Snyder SH, Zweier JL. Nitric oxide synthase generates superoxide and nitric oxide in arginine-depleted cells leading to peroxynitrite-mediated cellular injury. Proc. Natl Acad. Sci. USA 93(13), 6770-6774 (1996).

31 Chicoine LG, Paffett ML, Young TL, Nelin LD. Arginase inhibition increases nitric oxide production in bovine pulmonary arterial endothelial cells. Am. J. Physiol. Lung Cell Mol. Physiol. 287(1), L60-L68 (2004).

32 Hey C, Boucher JL, Vadon-Le Goff S, Ketterer G, Wessler I, Racke K. Inhibition of arginase in rat and rabbit alveolar macrophages by $\mathrm{N}$ omega-hydroxy-D, L-indospicine, effects on L-arginine utilization by nitric oxide synthase. $\mathrm{Br}$. J. Pharmacol. 121(3), 395-400 (1997).

33 Munder M, Eichmann K, Moran JM, Centeno F, Soler G, Modolell M. Th1/Th2-regulated expression of arginase isoforms in murine macrophages and dendritic cells. $J$. Immunol. 163(7), 3771-3777 (1999).

34 Gordon S. Alternative activation of macrophages. Nat. Rev. Immunol. 3(1), 23-35 (2003).

35 Fujii W, Ashihara E, Hirai $\mathrm{H}$ et al. Myeloid-derived suppressor cells play crucial roles in the regulation of mouse collagen-induced arthritis. J. Immunol. 191(3), 1073-1081 (2013).

$36 \mathrm{Xu}$ L, Hilliard B, Carmody RJ et al. Arginase and autoimmune inflammation in the central nervous system. Immunology 110(1), 141-148 (2003).

37 Corraliza I, Moncada S. Increased expression of arginase II in patients with different forms of arthritis. Implications of the regulation of nitric oxide. J. Rheumatol. 29(11), 2261-2265 (2002).

38 Wu H, Zhen Y, Ma Z et al. Arginase-1-dependent promotion of TH17 differentiation and disease progression by MDSCs in systemic lupus erythematosus. Sci. Transl. Med. 8(331), $331 \mathrm{ra} 340$ (2016).

39 Chakravortty D, Hensel M. Inducible nitric oxide synthase and control of intracellular bacterial pathogens. Microbes Infect 5(7), 621-627 (2003).

40 Das P, Lahiri A, Lahiri A, Chakravortty D. Modulation of the arginase pathway in the context of microbial pathogenesis: a metabolic enzyme moonlighting as an immune modulator. PLoS Pathog. 6(6), e1000899 (2010).

41 Munder M. Arginase: an emerging key player in the mammalian immune system. Br. J. Pharmacol. 158(3), 638-651 (2009).

42 Munder M, Schneider H, Luckner C et al. Suppression of T-cell functions by human granulocyte arginase. Blood 108(5), 1627-1634 (2006).

43 Kropf P, Baud D, Marshall SE et al. Arginase activity mediates reversible $\mathrm{T}$ cell hyporesponsiveness in human pregnancy. Eur. J. Immunol. 37(4), 935-945 (2007).

44 Rodriguez PC, Zea AH, Culotta KS, Zabaleta J, Ochoa JB, Ochoa AC. Regulation of $\mathrm{T}$ cell receptor CD3zeta chain expression by L-arginine. J. Biol. Chem. 277(24), 2112321129 (2002).

45 Taheri F, Ochoa JB, Faghiri Z et al. L-Arginine regulates the expression of the T-cell receptor zeta chain (CD3zeta) in Jurkat cells. Clin. Cancer. Res. 7(Suppl. 3), s958-s965 (2001).

46 Fallarino F, Grohmann U, You S et al. The combined effects of tryptophan starvation and tryptophan catabolites downregulate $\mathrm{T}$ cell receptor zeta-chain and induce a regulatory phenotype in naive T cells. J. Immunol. 176(11), 6752-6761 (2006).

47 Elahi S, Ertelt JM, Kinder JM et al. Immunosuppressive CD71+ erythroid cells compromise neonatal host defence against infection. Nature 504(7478), 158-162 (2013).

48 Edinger AL, Thompson CB. Antigen-presenting cells control T cell proliferation by regulating amino acid availability. Proc. Natl Acad. Sci. USA 99(3), 1107-1109 (2002).

49 Dunand-Sauthier I, Irla M, Carnesecchi $S$ et al. Repression of arginase- 2 expression in dendritic cells by microRNA-155 is critical for promoting $\mathrm{T}$ cell proliferation. J. Immunol. 193(4), 1690-1700 (2014).

50 Uyttenhove C, Pilotte L, Theate I et al. Evidence for a tumoral immune resistance mechanism based on tryptophan degradation by indoleamine 2,3-dioxygenase. Nat. Med. 9(10), 1269-1274 (2003).

51 Opitz CA, Litzenburger UM, Sahm F et al. An endogenous tumour-promoting ligand of the human aryl hydrocarbon receptor. Nature 478(7368), 197-203 (2011).

52 Lob S, Konigsrainer A, Zieker D et al. IDO1 and IDO2 are expressed in human tumors: levo- but not dextro-1-methyl tryptophan inhibits tryptophan catabolism. Cancer Immunol. Immun. 58(1), 153-157 (2009).

53 Munn DH, Sharma MD, Hou D et al. Expression of indoleamine 2,3-dioxygenase by plasmacytoid dendritic cells in tumor-draining lymph nodes. J. Clin. Invest. 114(2), 280-290 (2004).

54 Sharma MD, Baban B, Chandler P et al. Plasmacytoid dendritic cells from mouse tumor-draining lymph nodes directly activate mature Tregs via indoleamine 2,3-dioxygenase. J. Clin. Invest. 117(9), 2570-2582 (2007).

55 Ling WF, Zhang JM, Yuan ZR et al. Mesenchymal stem cells use IDO to regulate immunity in tumor microenvironment. Cancer Res. 74(5), 1576-1587 (2014).

56 Godin-Ethier J, Hanafi LA, Piccirillo CA, Lapointe R. Indoleamine 2,3-dioxygenase expression in human cancers: clinical and immunologic perspectives. Clin. Cancer. Res. 17(22), 6985-6991 (2011).

57 Folgiero V, Goffredo BM, Filippini P et al. Indoleamine 2,3-dioxygenase 1 (IDO1) activity in leukemia blasts correlates with poor outcome in childhood acute myeloid leukemia. Oncotarget 5(8), 2052-2064 (2014).

58 Muller AJ, Duhadaway JB, Donover PS, Sutanto-Ward E, Prendergast GC. Inhibition of indoleamine 2,3-dioxygenase, an immunoregulatory target of the cancer suppression gene 
Bin1, potentiates cancer chemotherapy. Nat. Med. 11(3), 312-319 (2005).

Balachandran VP, Cavnar MJ, Zeng S et al. Imatinib potentiates antitumor $T$ cell responses in gastrointestinal stromal tumor through the inhibition of Ido. Nat. Med. 17(9), U1094-U1099 (2011).

60 Basu GD, Tinder TL, Bradley JM et al. Cyclooxygenase-2 inhibitor enhances the efficacy of a breast cancer vaccine: role of IDO. J. Immunol. 177(4), 2391-2402 (2006).

61 Von Bergwelt-Baildon MS, Popov A, Saric T et al. CD25 and indoleamine 2,3-dioxygenase are up-regulated by prostaglandin E2 and expressed by tumor-associated dendritic cells in vivo: additional mechanisms of T-cell inhibition. Blood 108(1), 228-237 (2006).

62 Spranger S, Spaapen RM, Zha Y et al. Up-regulation of PD-L1, IDO, and T-regs in the melanoma tumor microenvironment is driven by CD8(+) T cells. Sci. Transl. Med. 5(200), 200ra116 (2013).

63 Silk JD, Lakhal S, Laynes R et al. IDO induces expression of a novel tryptophan transporter in mouse and human tumor cells. J. Immunol. 187(4), 1617-1625 (2011).

64 Kudo Y, Boyd CAR, Sargent IL, Redman CWG. Tryptophan degradation by human placental indoleamine 2,3-dioxygenase regulates lymphocyte proliferation. J. Physiol. 535(1), 207-215 (2001).

65 Munn DH, Sharma MD, Baban B et al. GCN2 kinase in T cells mediates proliferative arrest and anergy induction in response to indoleamine 2,3-dioxygenase. Immunity 22(5), 633-642 (2005).

66 Fallarino I, Grohmann U, Vacca C et al. T cell apoptosis by tryptophan catabolism. Cell Death Differ. 9(10), 1069-1077 (2002).

67 Lee SM, Lee YS, Choi JH et al. Tryptophan metabolite 3-hydroxyanthranilic acid selectively induces activated $\mathrm{T}$ cell death via intracellular GSH depletion. Immunol. Lett. 132(1-2), 53-60 (2010).

68 Iken K, Liu KF, Liu HZ et al. Indoleamine 2,3-dioxygenase and metabolites protect murine lung allografts and impair the calcium mobilization of T cells. Am. J. Respir. Cell Mol. Biol. 47(4), 405-416 (2012).

69 Eleftheriadis T, Pissas G, Antoniadi G, Spanoulis A, Liakopoulos V, Stefanidis I. Indoleamine 2,3-dioxygenase increases $\mathrm{p} 53$ levels in alloreactive human $\mathrm{T}$ cells, and both indoleamine 2,3-dioxygenase and $\mathrm{p} 53$ suppress glucose uptake, glycolysis and proliferation. Int. Immunol. 26(12), 673-684 (2014).

70 Timosenko E, Ghadbane H, Silk JD et al. Nutritional stress induced by tryptophan-degrading enzymes results in ATF4dependent reprogramming of the amino acid transporter profile in tumor cells. Cancer Res. 76(21), 6193-6204 (2016).

71 Chen W, Liang X, Peterson AJ, Munn DH, Blazar BR. The indoleamine 2,3-dioxygenase pathway is essential for human plasmacytoid dendritic cell-induced adaptive $T$ regulatory cell generation. J. Immunol. 181(8), 5396-5404 (2008).

72 Curti A, Pandolfi S, Valzasina B et al. Modulation of tryptophan catabolism by human leukemic cells results in the conversion of CD25(-) into CD25(+) T regulatory cells.
Blood 109(7), 2871-2877 (2007).

73 Liu XQ, Lu K, Feng LL et al. Up-regulated expression of indoleamine 2,3-dioxygenase 1 in non-Hodgkin lymphoma correlates with increased regulatory T-cell infiltration. Leuk. Lymphoma 55(2), 405-414 (2014).

74 Curti A, Trabanelli S, Onofri C et al. Indoleamine 2,3-dioxygenase-expressing leukemic dendritic cells impair a leukemia-specific immune response by inducing potent $\mathrm{T}$ regulatory cells. Haematologica 95(12), 2022-2030 (2010).

75 Cobbold SP, Adams E, Farquhar CA et al. Infectious tolerance via the consumption of essential amino acids and mTOR signaling. Proc. Natl Acad. Sci. USA 106(29), 12055-12060 (2009).

76 Mezrich JD, Fechner JH, Zhang XJ, Johnson BP, Burlingham WJ, Bradfield CA. An interaction between kynurenine and the aryl hydrocarbon receptor can generate regulatory T cells. J. Immunol. 185(6), 3190-3198 (2010).

77 Sharma MD, Hou DY, Liu YJ et al. Indoleamine 2,3-dioxygenase controls conversion of Foxp3(+) Tregs to TH17-like cells in tumor-draining lymph nodes. Blood 113(24), 6102-6111 (2009).

78 Pallotta MT, Orabona C, Volpi C et al. Indoleamine 2,3-dioxygenase is a signaling protein in long-term tolerance by dendritic cells. Nat. Immunol. 12(9), U870-U891 (2011).

79 Volpi C, Mondanelli G, Pallotta MT et al. Allosteric modulation of metabotropic glutamate receptor 4 activates IDO1-dependent, immunoregulatory signaling in dendritic cells. Neuropharmacology 102, 59-71 (2016).

80 Holmgaard RB, Zamarin D, Li YY et al. Tumor-expressed IDO recruits and activates MDSCs in a Treg-dependent manner. Cell Rep. 13(2), 412-424 (2015).

81 Romani L, Fallarino F, De Luca A et al. Defective tryptophan catabolism underlies inflammation in mouse chronic granulomatous disease. Nature 451(7175), U211U212 (2008).

82 Molano A, Illarionov PA, Besra GS, Putterman C, Porcelli SA. Modulation of invariant natural killer T cell cytokine responses by indoleamine 2,3-dioxygenase. Immunol. Lett. 117(1), 81-90 (2008)

83 Wang XF, Wang HS, Wang $\mathrm{H}$ et al. The role of indoleamine 2,3-dioxygenase (IDO) in immune tolerance: focus on macrophage polarization of THP-1 cells. Cell. Immunol. 289(1-2), 42-48 (2014).

84 Pietra G, Manzini C, Rivara S et al. Melanoma cells inhibit natural killer cell function by modulating the expression of activating receptors and cytolytic activity. Cancer Res. 72(6), 1407-1415 (2012).

85 Kai S, Goto S, Tahara K, Sasaki A, Kawano K, Kitano S. Inhibition of indoleamine 2,3-dioxygenase suppresses NK cell activity and accelerates tumor growth. J. Exp. Ther. Oncol. 3(6), 336-345 (2003).

86 Chang CI, Liao JC, Kuo L. Macrophage arginase promotes tumor cell growth and suppresses nitric oxide-mediated tumor cytotoxicity. Cancer Res. 61(3), 1100-1106 (2001).

87 Gannon PO, Godin-Ethier J, Hassler M et al. Androgenregulated expression of arginase 1, arginase 2 and interleukin-8 in human prostate cancer. PLoS ONE 5(8), 
e12107 (2010).

88 Singh R, Pervin S, Karimi A, Cederbaum S, Chaudhuri G. Arginase activity in human breast cancer cell lines: $\mathrm{N}$ (omega)-hydroxy-L-arginine selectively inhibits cell proliferation and induces apoptosis in MDA-MB-468 cells. Cancer Res. 60 (12), 3305-3312 (2000).

89 Suer Gokmen S, Yoruk Y, Cakir E, Yorulmaz F, Gulen S. Arginase and ornithine, as markers in human non-small-cell lung carcinoma. Cancer Biochem. Biophys. 17(1-2), 125-131 (1999).

90 Tate DJ Jr, Vonderhaar DJ, Caldas YA et al. Effect of arginase II on L-arginine depletion and cell growth in murine cell lines of renal cell carcinoma. J. Hematol. Oncol. 1, 14 (2008).

91 Cederbaum SD, Yu H, Grody WW, Kern RM, Yoo P, Iyer RK. Arginases I and II: do their functions overlap? Mol. Genet. Metab. 81(Suppl. 1), S38-S44 (2004).

92 Bronte V, Kasic T, Gri G et al. Boosting antitumor responses of $\mathrm{T}$ lymphocytes infiltrating human prostate cancers. J. Exp. Med. 201(8), 1257-1268 (2005).

$93 \mathrm{Wu} \mathrm{CW}, \mathrm{Chi} \mathrm{CW}$, Tsay SH et al. The effects of arginase on neoplasm. I. The role of arginase in the immunosuppressive effects of extract from gastric cancer. Zhonghua Min Guo Wei Sheng Wu Ji Mian Yi Xue Za Zhi 20(4), 279-289 (1987).

94 Wu CW, Chi CW, Lin EC, Lui WY, P'eng FK, Wang SR. Serum arginase level in patients with gastric cancer. J. Clin. Gastroenterol. 18(1), 84-85 (1994).

95 Porembska Z, Luboinski G, Chrzanowska A, Mielczarek M, Magnuska J, Baranczyk-Kuzma A. Arginase in patients with breast cancer. Clin. Chim. Acta 328(1-2), 105-111 (2003).

96 Adams JL, Smothers J, Srinivasan R, Hoos A. Big opportunities for small molecules in immuno-oncology. Nat. Rev. Drug Discov. 14(9), 603-622 (2015).

97 Bronte V, Apolloni E, Cabrelle A et al. Identification of a $\mathrm{CD} 11 \mathrm{~b}(+) / \mathrm{Gr}-1(+) / \mathrm{CD} 31(+)$ myeloid progenitor capable of activating or suppressing CD8(+) T cells. Blood 96(12), 3838-3846 (2000).

98 Bronte V, Serafini P, De Santo C et al. IL-4-induced arginase 1 suppresses alloreactive $\mathrm{T}$ cells in tumor-bearing mice. $\mathrm{J}$. Immunol. 170(1), 270-278 (2003).

99 Gabrilovich DI, Velders MP, Sotomayor EM, Kast WM. Mechanism of immune dysfunction in cancer mediated by immature Gr-1+ myeloid cells. J. Immunol. 166(9), 5398-5406 (2001).

100 Kusmartsev S, Nefedova Y, Yoder D, Gabrilovich DI. Antigen-specific inhibition of CD8 + T cell response by immature myeloid cells in cancer is mediated by reactive oxygen species. J. Immunol. 172(2), 989-999 (2004).

101 Mazzoni A, Bronte V, Visintin A et al. Myeloid suppressor lines inhibit $\mathrm{T}$ cell responses by an NO-dependent mechanism. J. Immunol. 168(2), 689-695 (2002).

102 Vasquez-Dunddel D, Pan F, Zeng Q et al. STAT3 regulates arginase-I in myeloid-derived suppressor cells from cancer patients. J. Clin. Invest. 123(4), 1580-1589 (2013).

103 Rutschman R, Lang R, Hesse M, Ihle JN, Wynn TA, Murray PJ. Cutting edge: Stat6-dependent substrate depletion regulates nitric oxide production. J. Immunol. 166(4), 2173-2177 (2001).
104 Rodriguez PC, Quiceno DG, Zabaleta J et al. Arginase I production in the tumor microenvironment by mature myeloid cells inhibits T-cell receptor expression and antigenspecific T-cell responses. Cancer Res. 64(16), 5839-5849 (2004).

105 Bak SP, Alonso A, Turk MJ, Berwin B. Murine ovarian cancer vascular leukocytes require arginase-1 activity for T cell suppression. Mol. Immunol. 46(2), 258-268 (2008).

106 Serafini P, Mgebroff S, Noonan K, Borrello I. Myeloidderived suppressor cells promote cross-tolerance in B-cell lymphoma by expanding regulatory $\mathrm{T}$ cells. Cancer Res. 68(13), 5439-5449 (2008).

107 Rodriguez PC, Ernstoff MS, Hernandez C et al. Arginase I-producing myeloid-derived suppressor cells in renal cell carcinoma are a subpopulation of activated granulocytes. Cancer Res. 69(4), 1553-1560 (2009).

108 De Boniface J, Mao Y, Schmidt-Mende J, Kiessling R, Poschke I. Expression patterns of the immunomodulatory enzyme arginase 1 in blood, lymph nodes and tumor tissue of early-stage breast cancer patients. Oncoimmunology 1(8), 1305-1312 (2012).

109 Jacobsen LC, Theilgaard-Monch K, Christensen EI, Borregaard N. Arginase 1 is expressed in myelocytes/ metamyelocytes and localized in gelatinase granules of human neutrophils. Blood 109 (7), 3084-3087 (2007).

110 Zea AH, Rodriguez PC, Atkins MB et al. Arginaseproducing myeloid suppressor cells in renal cell carcinoma patients: a mechanism of tumor evasion. Cancer Res. 65(8), 3044-3048 (2005).

111 Mussai F, De Santo C, Abu-Dayyeh I et al. Acute myeloid leukemia creates an arginase-dependent immunosuppressive microenvironment. Blood 122(5), 749-758 (2013).

112 Balkwill F, Charles KA, Mantovani A. Smoldering and polarized inflammation in the initiation and promotion of malignant disease. Cancer Cell 7(3), 211-217 (2005).

113 Pucci F, Venneri MA, Biziato D et al. A distinguishing gene signature shared by tumor-infiltrating Tie2-expressing monocytes, blood 'resident' monocytes, and embryonic macrophages suggests common functions and developmental relationships. Blood 114(4), 901-914 (2009).

114 Lissbrant IF, Stattin P, Wikstrom P, Damber JE, Egevad L, Bergh A. Tumor associated macrophages in human prostate cancer: relation to clinicopathological variables and survival. Int. J. Oncol. 17(3), 445-451 (2000).

115 Ochoa AC, Zea AH, Hernandez C, Rodriguez PC. Arginase, prostaglandins, and myeloid-derived suppressor cells in renal cell carcinoma. Clin. Cancer. Res. 13(2 Pt 2), 721s-726s (2007).

116 Redente EF, Orlicky DJ, Bouchard RJ, Malkinson AM. Tumor signaling to the bone marrow changes the phenotype of monocytes and pulmonary macrophages during urethaneinduced primary lung tumorigenesis in $\mathrm{A} / \mathrm{J}$ mice. Am. J. Pathol. 170 (2), 693-708 (2007).

117 Ino Y, Yamazaki-Itoh R, Oguro S et al. Arginase II expressed in cancer-associated fibroblasts indicates tissue hypoxia and predicts poor outcome in patients with pancreatic cancer. PLoS ONE 8(2), e55146 (2013). 
118 Hou DY, Muller AJ, Sharma MD et al. Inhibition of indoleamine 2,3-dioxygenase in dendritic cells by stereoisomers of 1-methyl-tryptophan correlates with antitumor responses. Cancer Res. 67(2), 792-801 (2007).

119 Koblish HK, Hansbury MJ, Bowman KJ et al. Hydroxyamidine inhibitors of indoleamine-2,3-dioxygenase potently suppress systemic tryptophan catabolism and the growth of IDO-expressing tumors. Mol. Cancer Ther. 9(2), 489-498 (2010).

120 Li M, Bolduc AR, Hoda MN et al. The indoleamine 2,3-dioxygenase pathway controls complement-dependent enhancement of chemo-radiation therapy against murine glioblastoma. J. Immunother. Cancer 2, 21 (2014).

121 Sugimoto H, Oda SI, Otsuki T, Hino T, Yoshida T, Shiro Y. Crystal structure of human indoleamine 2,3-dioxygenase: catalytic mechanism of O-2 incorporation by a hemecontaining dioxygenase. Proc. Natl Acad. Sci. USA 103(8), 2611-2616 (2006).

122 Mellor AL, Baban B, Chandler P et al. Cutting edge: induced indoleamine 2,3 dioxygenase expression in dendritic cell subsets suppresses $\mathrm{T}$ cell clonal expansion. J. Immunol. 171(4), 1652-1655 (2003).

123 Holmgaard RB, Zamarin D, Munn DH, Wolchok JD, Allison JP. Indoleamine 2,3-dioxygenase is a critical resistance mechanism in antitumor $\mathrm{T}$ cell immunotherapy targeting CTLA-4. J. Exp. Med. 210 (7), 1389-1402 (2013).

124 Soliman HH, Jackson E, Neuger T et al. A first in man Phase I trial of the oral immunomodulator, indoximod, combined with docetaxel in patients with metastatic solid tumors. Oncotarget 5(18), 8136-8146 (2014).

125 Zakharia Y, Drabick J, Khleif S et al. Results of Phase 1b trial of the indoleamine 2,3-dioxygenase (IDO) pathway inhibitor indoximod plus ipilimumab for the treatment of unresectable stage III or IV melanoma. Eur. J. Cancer 51, S108-S108 (2015).

126 Soliman HH, Minton SE, Ismail-Khan R et al. A Phase 1/2 study of Ad.p53 DC vaccine with indoximod immunotherapy in metastatic breast cancer. Cancer Res. doi:10.1158/15387445.SABCS14-P2-15-04 75(9), (2015).

127 Gibney G, Hamid O, Lutzky J et al. Updated results from a Phase 1/2 study of epacadostat (INCB024360) in combination with ipilimumab in patients with metastatic melanoma. Eur. J. Cancer 51, S106-S107 (2015).

128 Lee SY, Choi HK, Lee KJ et al. The immune tolerance of cancer is mediated by IDO that is inhibited by COX-2 inhibitors through regulatory T cells. J. Immunother. 32(1), 22-28 (2009).
129 Iachininoto MG, Nuzzolo ER, Bonanno G et al. Cyclooxygenase-2 (COX-2) inhibition constrains indoleamine 2,3-dioxygenase 1 (IDO1) activity in acute myeloid leukaemia cells. Molecules 18(9), 10132-10145 (2013).

130 Davies NM, Jamali F. COX-2 selective inhibitors cardiac toxicity: getting to the heart of the matter. J. Pharm. Pharm. Sci. 7(3), 332-336 (2004).

131 Andersen MH. Immune regulation by self-recognition: novel possibilities for anticancer immunotherapy. J. Natl Cancer Inst. doi:10.1093/jnci/djv154 107(9), (2015).

132 Iversen TZ, Engell-Noerregaard L, Ellebaek E et al. Longlasting disease stabilization in the absence of toxicity in metastatic lung cancer patients vaccinated with an epitope derived from indoleamine 2,3 dioxygenase. Clin. Cancer Res. 20(1), 221-232 (2014).

133 Bjoern J, Iversen TZ, Nitschke NJ, Andersen MH, Svane IM. Safety, immune and clinical responses in metastatic melanoma patients vaccinated with a long peptide derived from indoleamine 2,3-dioxygenase in combination with ipilimumab. Cytotherapy 18(8), 1043-1055 (2016).

134 Rodriguez PC, Ochoa AC. T cell dysfunction in cancer: role of myeloid cells and tumor cells regulating amino acid availability and oxidative stress. Semin. Cancer Biol. 16(1), 66-72 (2006).

135 Works M, Bennett M, Chen JJ et al. Immuno-oncology agent CB-1158 is a potent and selective arginase inhibitor and causes an immune-mediated anti-tumor response. Presented at: AACR 107th Annual Meeting. New Orleans, LA, USA, 16-20 April 2016.

136 Crittenden MR, Savage T, Cottam B et al. Expression of arginase I in myeloid cells limits control of residual disease after radiation therapy of tumors in mice. Radiat. Res. 182(2), 182-190 (2014).

137 Gupta S, Ahmad N, Marengo SR, Maclennan GT, Greenberg NM, Mukhtar H. Chemoprevention of prostate carcinogenesis by alpha-difluoromethylornithine in TRAMP mice. Cancer Res. 60 (18), 5125-5133 (2000).

138 Serafini P, Meckel K, Kelso M et al. Phosphodiesterase-5 inhibition augments endogenous antitumor immunity by reducing myeloid-derived suppressor cell function. J. Exp. Med. 203(12), 2691-2702 (2006).

139 Imai K, Takaoka A. Comparing antibody and small-molecule therapies for cancer. Nat. Rev. Cancer 6(9), 714-727 (2006). 
